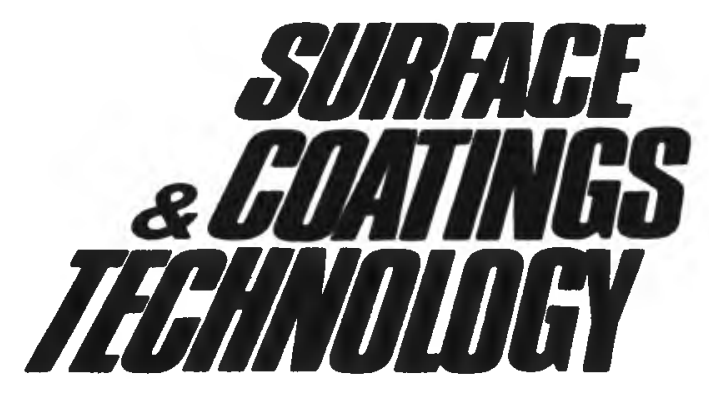

Surface and Coatings Technology 116-119 (1999) 848-852

\title{
Elastomer treatment by arc metal deposition assisted with self-ion irradiation
}

I.S. Tashlykov ${ }^{\text {a, * , V.I. Kasperovich }}{ }^{\text {b }}$ M.G. Shadrukhin ${ }^{\text {b }, ~ A . V . ~ K a s p e r o v i c h ~}{ }^{\text {a }}$, G.K. Wolf ${ }^{c}$, W. Wesch ${ }^{\text {d }}$

- Belorussian State Technological University, 13-a Sverdlova str., 220630 Minsk, Byelorussia

b Joint-stock Company Belarusresinotechnika, 102 Minskaya str., 213829 Bobruysk, Byelorussia

'Institute for Applied Physical Chemistry, University of Heidelberg, Im Newenheimer Feld 500, D-69120 Heidelberg, Germany

'Institute of Solid State Physics, Max-Wien-Platz 1, D-07743 Jena, Germany

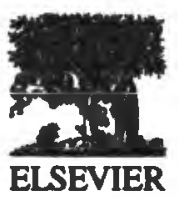




\title{
Elastomer treatment by arc metal deposition assisted with self-ion irradiation
}

\author{
I.S. Tashlykov ${ }^{\text {a, }}{ }^{\text {, V.I. Kasperovich }}{ }^{\text {b }}$, M.G. Shadrukhin ${ }^{\text {b }}$, A.V. Kasperovich ${ }^{\text {a }}$, \\ G.K. Wolf ${ }^{\mathrm{c}}$, W. Wesch ${ }^{\mathrm{d}}$ \\ a Belorussian State Technological University, 13-a Sverdlova str., 220630 Minsk, Byelorussia \\ ' Joint-stock Company Belarusresinotechnika, 102 Minskaya str., 213829 Bobruysk, Byelorussia \\ ${ }^{\mathrm{c}}$ Institute for Applied Physical Chemistry, University of Heidelberg, Im Neuenheimer Feld 500, D-69120 Heidelberg, Germany \\ d Institute of Solid State Physics, Max-Wien-Platz 1, D-07743 Jena, Germany
}

\begin{abstract}
The problems of the friction of elastomer articles in contact with other parts, involved in a rotating or reciprocating motion, mould release and mould fouling in rubber industry have prompted research into the deposition of metal layers on rubber. In this paper, the surface layer and the interface formed by self-ion-assisted deposition (SIAD) of metals (Me) on vulcanized synthetic rubber are examined with the aim of understanding better the factors that influence the adhesion. The level of adhesion between the deposited layer and rubber was measured using the Pin Pull Test method. The SIAD modified surfaces were examined using RBS and electron diffraction techniques. The results revealed that the composition of the Me-based layers deposited on rubber in conjunction with self-ion irradiation exhibited many component content of coating and a weak dependence on metal species. The layer consists of $\mathrm{Me}$, carbon, oxygen and hydrogen derived from the residual vacuum and vacuum oil and silicon from isolators of electrodes in an ion source. It was found that the species of Me exerts a strong influence on the friction of elastomer against steel and on the bonding between the coating and rubber. The work concludes that the adhesion between the rubber and the coating depends upon the chosen compound coating and can be controlled variably. (C) 1999 Elsevier Science S.A. All rights reserved.
\end{abstract}

Keywords: Adhesion; Elastomer; Self-ion-assisted deposition layers

\section{Introduction}

Coating of solids has been widely used for protection and modification of articles and materials having optimum bulk properties. In applications, strong adherence of a coating to a material is extremely important. Among a number of techniques simple vacuum evaporation of thin films was found to be relatively simple to apply and rather effective. In many cases, however, the film adherence to the substrate is insufficient, and coatings are under high stress $[1,2]$. Both parameters are crucial when the substrate is not a rigid material but is made of elastomer or rubber. Therefore, we may consider that the deposition of thin layers on an elastomer and the investigation of the modified surface macroscopic coupled with microscopic (atomic scale) properties are important for many applications in materials science and engineering, particularly in the rubber industry.

\footnotetext{
* Corresponding author. Tel.: + 375-1722-71091; fax: + 375-1722-61075.

E-mail address: root@bgtu.minsk.by (I.S. Tashlykov)
}

An improvement in adherence of films is obtained if the deposition of the coating is followed by an ion beam mixing (IBM) procedure [3] or at the surface of a growing film, IBM is provided, for example using ion-beamassisted deposition techniques [4,5]. These methods have a common factor in that they use evaporation plus a reactive or noble gas ion bombardment. However, in such circumstances, a sufficiently large $\mathrm{N}$ or $\mathrm{Ar}(\mathrm{Kr}, \mathrm{Xe})$ concentration in the interfacial film-substrate region may be obtained $[6,7]$.

In our work, we have fabricated coating/rubber $(\mathrm{Co} / \mathrm{R})$ structures by a method that we call the self-ionassisted deposition technique $[8,9]$. Also, we have examined the composition of thin films, and the effect of $\mathrm{Me}$ deposition on the friction of treated rubber against steel and on the bonding between rubber and the coating.

\section{Experimental}

SIAD experiments were performed using a resonance vacuum arc ion source. This type of ion source with 
desirable $\mathrm{Me}$ electrodes was used to produce a mixture of neutral $\mathrm{Me}$ and $\mathrm{Me}^{+}$ion species. The relative ratio of ions/neutral atoms (I/A) could changed by varying the target-source separation distance since the neutrals follow an approximately cosine distribution, whereas the ions are directed by the electric field (thus, a smaller distance means relatively fewer $\mathrm{Me}^{+}$ions), or by changing the frequency (tuning) of the source supply. Rubber plates were floated to a negative potential with respect to the source of between 9 and $20 \mathrm{keV}$ to accelerate the ion species. The deposition and irradiation of brass, titanium, chromium, zirconium, molybdenum and tungsten coatings has been accomplished on rubber (GOST 7-IRP-1068) samples and onto the working surface of seals. The base pressure in the target chamber was about $10^{2} \mathrm{~Pa}$. The I/A ratios and deposition rates were found to be $0.1-0.3$ and $1-4 \AA / s$ in different sets of experiments.

The Rutherford backscattering technique was employed for investigating the target composition and for depth profiling of components in the prepared $\mathrm{Co} / \mathrm{R}$ structures. The experimental data were compared with a RUMP code computer simulation of the target content [10]. The energy of $\mathrm{He}^{+}$ions was $1.8 \mathrm{MeV}$, and the scattering angle, entry angle and escape angle were 170 , 0 and $10^{\circ}$, respectively. The energy resolution of the analyzing system was $15 \mathrm{keV}$ corresponding to a depth resolution of about $20 \mathrm{~nm}$.

SEM was used to investigate the topographical properties of the modified surface.

Tribological tests were conducted, employing an apparatus 'Dnepr-2' for measuring friction force against rotating steel shaft and a device TAU-3M for determining friction in a reciprocating motion against steel. The cteel pin was translated reciprocally under non-lubricated conditions against modified rubber counterfaces at constant pressure and a sliding speed range of 0.1 $0.2 \mathrm{~cm} / \mathrm{s}$.

The adhesion between the film and rubber was measured using a Pin Pull Test. Five pins were fixed with glue at every rubber plate, modified by SIAD. The standard preparation and conditions of the tests were the same as those used by Wolf [11].

\section{Results}

An RBS spectrum of a sample upon which the Mo coating was deposited and also irradiated with $\mathrm{Mo}^{+}$ lons (2) is compared to a spectrum of initial rubber (1), Fig. 1. Vertical marks indicate the positions of signals trom identified elements entering into the elastomer pomposition and the modified rubber. It can be clearly that Mo deposition is accompanied by the appearence of oxygen, carbon and silicon in the film. We chould emphasize that a more or less similar behaviour

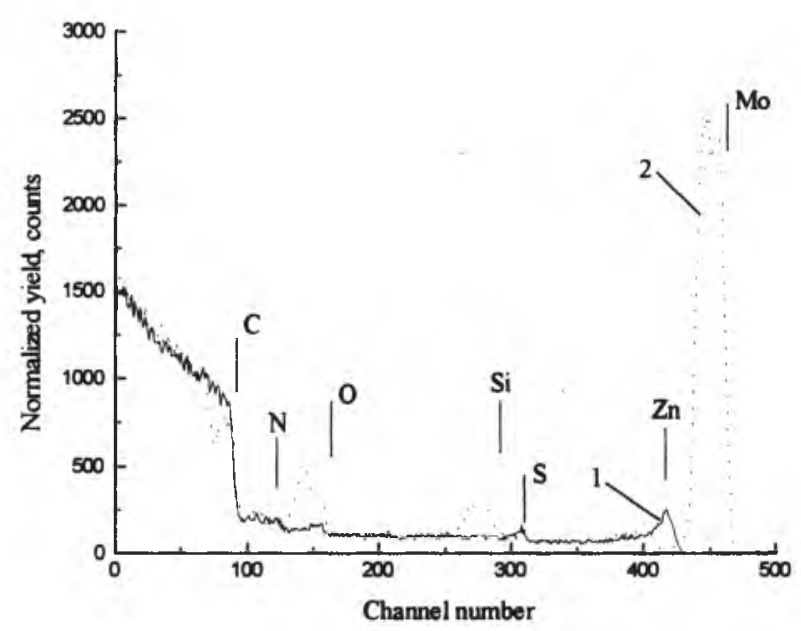

Fig. 1. RBS spectra of initial rubber - solid curve (1) and with a deposited molybdenum layer - dot curve (2).

of the other metal deposited on rubber by means of SIAD was observed.

Table 1 presents the composition of the same (Fig. 1) samples. The data are obtained using the RUMP code simulation [10]. We can observe a relatively constant content of elements in the bulk of the rubber, but a very thin surface layer reveals a high concentration of several components that we presume is a result of outdiffusion of $\mathrm{Zn}$ and $\mathrm{S}$, which forms a chemical compound with $\mathrm{O}$ and $\mathbf{N}$. The $\mathrm{Mo} / \mathrm{R}$ structure is characterized by an approximately constant concentration of the analyzed components within it. We suppose that a significant level of $\mathrm{H}, \mathrm{C}, \mathrm{O}$ in a deposited layer is associated with the poor vacuum in the ion source chamber, which allows deposition of hydrocarbons onto the growing film during ion bombardment.

Silicon appears in the deposited film because of sputtering isolators of electrodes during the process of deposition.

It is known [11] that one of the most important factors responsible for good adhesion of coating on a substrate is physical linking by interface broadening. Such broadening is associated with metal and carbon (from rubber) atoms intermixing in the $\mathbf{C o} / \mathbf{R}$ interface region within cascades of atomic collisions. The amount of average energy density deposited in elastic collisions processes in $20 \mathrm{keV}$ molybdenum irradiated rubber is estimated using the approximation of Ref. [12] at $0.05 \mathrm{eV} / \mathrm{at}$, and the projected ion range and struggling are estimated at 36 and $9 \mathrm{~nm}$, respectivoly [13]. This indicates that in the first stage of the SIAD process, metal atoms may penetrate relatively dooply into the elastomer, providing an enhanced adhesion of the deposited layer to the substrate.

However, in the-case of elastomer or rubber containing composites, the situation is more complicated because accelerated ions that are supposed to improve 
Table 1

Composition of initial rubber and Mo layer deposited on rubber by means of SIAD

\begin{tabular}{|c|c|c|c|c|c|c|c|c|}
\hline \multirow[t]{2}{*}{ Layer } & \multicolumn{8}{|c|}{ Content (at.\%) of chemical elements } \\
\hline & $\mathrm{H}$ & $\mathrm{C}$ & $\mathbf{N}$ & $\mathrm{O}$ & $\mathrm{Si}$ & $\mathrm{s}$ & $\mathrm{Zn}$ & $\mathrm{Mq}$ \\
\hline Bulk rubber & 47.67 & 49.00 & 1.40 & 1.50 & - & 0.38 & 0.15 & - \\
\hline Surface rubber layer $(10 \mathrm{~nm})$ & - & 37.00 & 20.00 & 20.00 & - & 8.00 & 15.00 & - \\
\hline Mo layer $(100 \mathrm{~nm})$ & 47.00 & 40.00 & - & 6.00 & 2.50 & - & - & 4.51 \\
\hline
\end{tabular}

${ }^{\mathrm{a}} E_{\mathrm{Mo}^{+}}=20 \mathrm{keV}$.

the adhesion will simultaneously also destroy the rubber network. Therefore, direct measurements of the pooloff force need to be conducted. The data of our measurements are shown in Fig. 2. This figure provides an evidence suggesting that the SIAD process may improve adhesion $(\mathrm{Cr}, \mathrm{Zr}, \mathrm{Mo})$. In the case of $\mathrm{Ti}$ and $\mathrm{W}$, the situation is different. The large difference between two groups of metals $(\mathrm{Cr}, \mathrm{Zr}$, Mo and $\mathrm{Ti}, \mathrm{W})$ is a striking effect. This may signify that for poor adhesion of films based on Ti and $\mathrm{W}$, weak chemical or physical bonds across the interface are responsible. These data affirm the opinion $[11,14]$ that the chemical nature of metal in an interface region is an important factor for the level of adhesion of films on a substrate.

The surface of initial rubber shows no periodical or aligned topography. However, after the surface modification by means of SIAD, a complicated quasi-periodical structure can be observed when examined in the SEM, as shown in Fig. 3. The presence of quasi-periodical topography on layers produced by ion-assisted deposition is known [5] and was explained quantitatively on a basis of a build-up in stress [2]. In the case of the modification of the rubber surface by SIAD, 'wrinkling' of the deposited layers can be significantly promoted by the non-rigid nature of a substrate.

A destructive study of an initial and modified rubber

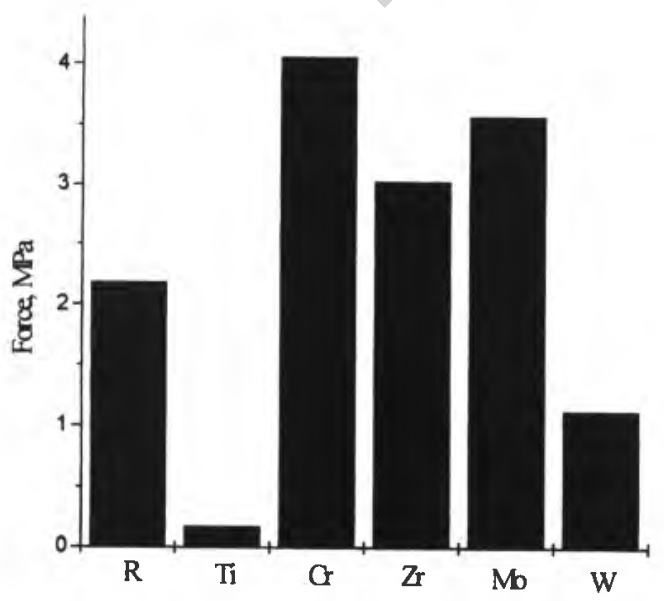

Fig. 2. Adhesion of Me SIAD coatings on rubber measured using the Pin Pull Test. $E_{\mathrm{Ti}^{+}, \mathrm{Mo}^{+}, \mathrm{w}}^{+}=20 \mathrm{keV}, E_{\mathrm{Cr}^{+}, \mathrm{Zr}^{+}}=10 \mathrm{keV}$. R-Pin Pull Test on initial rubber.

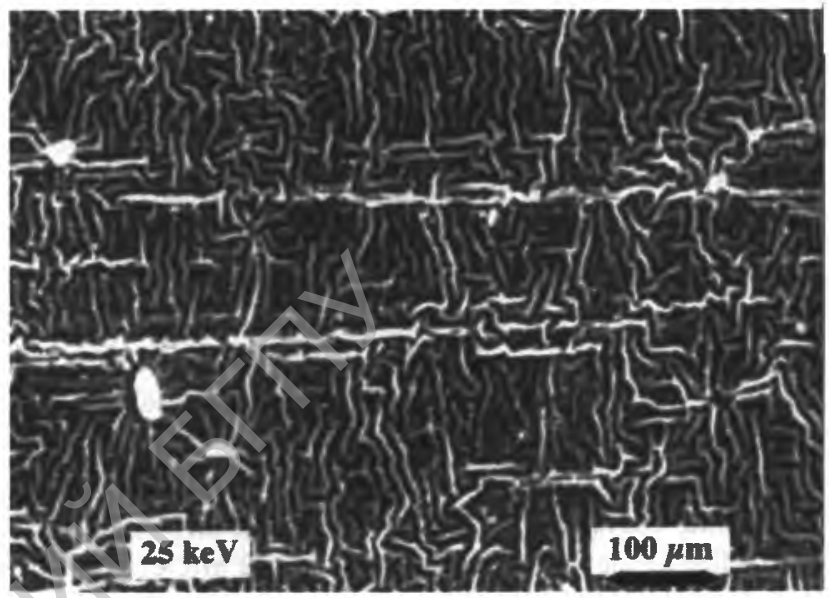

Fig. 3. SEM image of rubber surface modified by $\mathrm{Cr} . E_{\mathrm{Cr}^{+}}=10 \mathrm{keV}$.

friction against steel has been conducted, and the measured data are presented in Fig. 4. Dry sliding of the pin (the diameter of the curve was $5 \mathrm{~mm}$ ) against initia rubber under the loading of $20 \mathrm{~g}$ causes a continuous increase in friction force from 8.9 to 16.5 arb. units (a.u.) (direct output signal in an oscillograph) after 900 cycles (as shown in curve 1) when the rubber surface becomes destroyed. The similar behavior of Mo-covered rubber was observed only in the first sliding stage where the friction force increased from 6.8 to 11 a.u. after approxi-

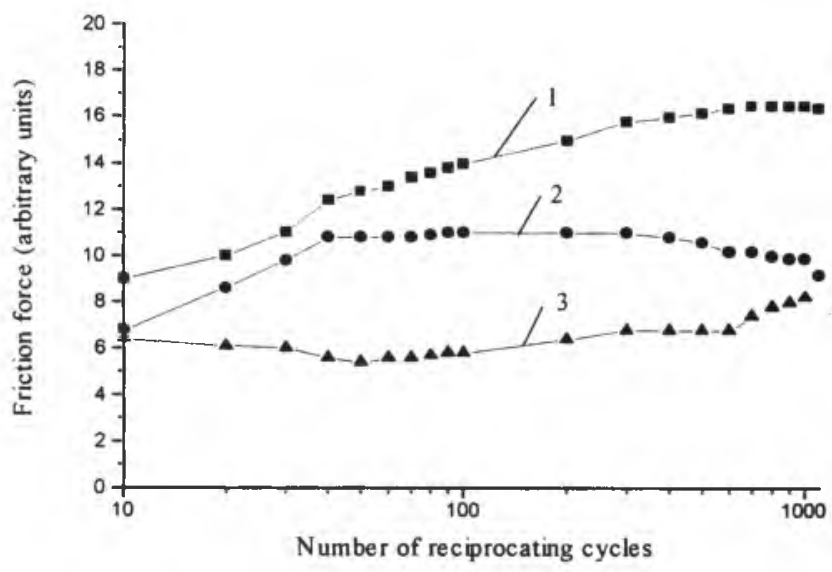

Fig. 4. Friction force of rubber sliding against steel pin as a function of reciprocating cycles. Initial rubber-1, Mo deposited on rubber$2, \mathrm{~W}$ deposited on rubber -3 . 
mately 50 reciprocal cycles (as shown in curve 2 in Fig. 4) but then stayed constant up to approximately 300 cycles of movement, slowly decreasing to 9 a.u. at 1000 testing cycles. As one would expect, the friction force of the steel pin translating under non-lubricated conditions against $\mathrm{W}$-modified rubber decreases slowly to 0.9 of its initial value after $40-50$ cycles of sliding (curve 3 in Fig. 4), and then this parameter increases gradually up to 9 a.u. after 1000 cycles of testing. The frictional forces of Mo- and W-modified rubber after 1500 cycles of the pin movement are similar and amount to 0.55 of the friction force value of the initial rubber after the same testing.

The non-destructive measurements of the friction force between seals against the rotating steel shaft confirm the improvement of tribological properties of the SIAD-modified rubber. The data shown in Table 2 reveal the drop in force of friction of the modified seals to $0.8-1.3 \mathrm{~N}$.

This is near $50-60 \%$ of the friction force of the seal without deposited coatings and may be compared with the data in Fig. 4.

The behavior of the decreasing force can be explained on the basis of the known fact [15] that the real area of contact between two solid surfaces and particularly between a modified rubber surface against a rotating steel shaft or sliding steel pin [16] is much smaller than the apparent area of the contacting bodies. The SEM image of $\mathrm{Cr}$ modified rubber, Fig. 3, where one can observe a 'wavy' structure of the coating surface with a wavelength of 8-10 $\mu$, confirms such a feature. The true area of contact in a friction process can be estimated only roughly taking into count a non-rigid nature of rubber. However, the proposed mechanism can be applied for a quantitative explanation of a macroscopic effect of the friction force decreasing between a metal sliding or rolling against the surface of the modified rubber.

In addition to the mechanism proposed above, we can consider created by SIAD coatings as films whose composition may be compared with that of solid lubricant films [15]. In fact, according to the data shown in Fig. 1 and presented in Table 1 the composition of coatings may include up to $\sim 40$ at $\%$ of carbon and $\sim 20-30$ at\% of oxygen. It is well known [14] that carbon-based compounds and oxide films are materials proposed for solid lubricant films. Therefore, in relation to the chemical nature of oxygen and carbon in coatings (this should be a subject for a future investigation), these elements potentially may play an essential role in the modification of friction phenomena between coated rubber and steel surfaces. It is clear that the tribological behavior of rubber is complicated, and we are far from understanding it completely. For example, we did not study the fate of metal-based layers when they were tensile-stressed in the field of a high-friction tribocontact under a particular load. However, some of the preliminary results of commercial tests of SIAD modified seals at the Joint-Stock Company GAZ are promising [17].

\section{Conclusions}

The composition and structure of the films formed by depositing brass, titanium, chromium, zirconium, molybdenum and tungsten onto rubber using SIAD have been investigated. Under vacuum conditions (with a base pressure of $100 \mathrm{~Pa}$ ) with an ion:atom ratio of $0.1-0.3$ and rate of deposition of $1-4 \AA / s$, the films included not only $\mathrm{Me}$ atoms but also carbon, oxygen, silicon and hydrogen, which originate from poor vacuum conditions with substantial hydrocarbon contamination. The role of the contamination is still questionable, but one may notice that the composition of the films produced by means of SIAD is comparable with the composition of solid lubricant films.

Changes in ion energy between 9 and $20 \mathrm{keV}$ did not appear to change the composition but, for a higher energy, the film thickness was reduced similar to the trend found in earlier studies of graphite [8] in the energy range $7-25 \mathrm{keV}$ and attributed to an increase in re-sputtering.

Tribological tests on Me ion-assisted deposited layers on rubber showed a substantial reduction in friction force against a rotating steel shaft and a sliding steel pin under non-lubricated conditions. The improvement of the tribological behavior between the active sites on the rolling/sliding counterface may reduce the friction characteristics up to more than a factor of two, but this depends on the deposited species and is sensitive to the regime of the film deposition. The observed results are attributed to a decrease in real contact area between the modified rubber and the steel shaft or pin due to the 'wavy' structure of the coating surface.

Table 2

Friction characteristic of modified seals against a rotating steel shaft

\begin{tabular}{lllll}
\hline Deposited species & Initial rubber & Brass & Titanium & Molybdenum \\
\hline Energy of ions $(\mathrm{keV})$ & - & 20 & 20 \\
Fluence of ions $\left(10^{16} \mathrm{~cm}^{-2}\right)$ & - & 2.0 & 15.0 & 9 \\
Force of friction $(\mathrm{N})$ & $1.5-2.0$ & $0.9-1.3$ & $1.0-1.3$ & 5.3 \\
\hline
\end{tabular}


The Pull Tests of the modified rubber reveal a strong influence of the chemical nature of the metals on the adhesion between the rubber and the film, suggesting that the adhesive force can be controlled variably.

\section{Acknowledgements}

Part of this work has been carried out under a DAAD grant. Financial support of the Deutsche Akademische Austausch Dienst is gratefully acknowledged. The author (I.S.T.) wants to thank H.J. Kersten for the PinPull Tests.

\section{References}

[1] F.M. d'Heurle, J.M.E. Harper, Thin Solid Films 17 (1989) 81.

[2] Yu.V. Martynenko, G. Carter, Radiat. Eff. Defects Solids 132 (1994) 103.
[3] M. Hirano, S. Miyake, Appl. Phys. Lett. 47 (1985) 683.

[4] G.K. Wolf, J. Vac. Sci. Technol. A 10 (1994) 1757.

[5] J.S. Colligon, J. Vac. Sci. Technol. A 13 (1995) 1649.

[6] I.S. Tashlykov, I.M. Belyi, O.G. Bobrovich, S. Kalbitzer, O Meyer, G.K. Wolf, B. Enders, Nucl. Instrum. Meth. Phys. Res B 80/81 (1993) 98.

[7] I.S. Tashlykov, G. Carter, J.S. Colligon, Mater. Sci. Forum 248 249 (1997) 357.

[8] I.S. Tashlykov, O.G. Bobrovich, V.Ch. Palchekh, V.V. Tuljev N.V. Alov, V.S. Kulikauskas, G.K. Wolf, Surf. Coat. Technol 74/75 (1995) 945.

[9] A positive decision (03.03.1998) on the inventor's applicatio1 No. 1851 applied for the patent of Republic of Belarus.

[10] L. Doolittle, Nucl. Instrum. Meth. B 9 (1985) 344.

[11] G.K. Wolf, Surf. Coat. Technol. 43/44 (1990) 920.

[12] P. Sigmund, Appl. Phys. Lett. 25 (1974) 169.

[13] J.F. Ziegler, J.P. Biersack, U. Littmark, The Stopping and Rang of Ions in Solids Vol. 1 Pergamon Press, New York, 1985, 321 pp

[14] M. Lotfipour, D.E. Packham, T.M. Turner, Surf. Interf. Anal. 1' (1991) 516.

[15] Y. Pauleau, Materials and Processes for Surface and Interfac Engineering, Y. Pauleau (Ed.), NATO ASI Series Vol. 290 Kluwer Academic, Dordrecht, 1995, p. 475.

[16] Y. Fukahori, H. Yamazaki, Wear 188 (1995) 19.

[17] S.A. Batjanov, personal communication. 